\title{
INSTITUTE OF REAL ESTATE STATE REGISTRATION AND NOTARIAL CERTIFICATION OF TRANSACTIONS AS A WHOLE ELEMENT OF THE CIVIL TURNOVER STABILITY: LEGISLATION INNOVATIONS
}

\author{
Elena V. Smirenskaya \\ Saint Petersburg State University, Saint Petersburg, Russian Federation
}

\begin{abstract}
Introduction: real estate represents the main material value for all civil turnover participants and for citizens it is sometimes the only material value, the rights for which are subject to the state registration. At the same time, state registration is not enough for protecting rights and legitimate interests of owners. Additional guarantees are necessary. The notarial certification of real estate transactions can give such guarantees. This legal mechanism is not new to our legislation, but due to the lack of requirements on the mandatory notarial form, unfortunately, it has been hardly ever used in civil turnover. The objective of the research is to study the interaction of two legal mechanisms directed to stability of civil turnover at the stage of reforming civil legislation. Methods: the methodological basis of this research is a set of the methods of scientific knowledge, among which the main are the comparative and legal method and the method of the analysis. Results: the paper presents the author's position on the necessity of setting standards on mandatory notarial certification of real estate transactions which relies on the last changes in legislation and shows the scientific and practical points of view as well. Conclusions: the research reveals the direct interaction and complementarity between the notarial certification of transactions and the state registration of real estate rights as a whole element of stability and legitimacy of the civil turnover. The article establishes that the unity of these legal mechanisms allow to protect the owners' rights and legitimate interests in the best way, and eliminate any further dispute of the registered rights.

Key words: real estate rights, real estate state registration, notarial certification of transactions, real estate transactions, mandatory form, registration procedure, Unified Information System of Notaries.

Citation. Smirenskaya E.V. Institute of Real Estate State Registration and Notarial Certification of Transactions as a Whole Element of the Civil Turnover Stability: Legislation Innovations. Legal Concept, 2019, vol. 18, no. 1, pp. 30-39. (in Russian). DOI: https://doi.org/10.15688/lc.jvolsu.2019.1.4
\end{abstract}

\section{ИНСТИТУТ ГОСУДАРСТВЕННОЙ РЕГИСТРАЦИИ НЕДВИЖИМОСТИ И НОТАРИАЛЬНОЕ УДОСТОВЕРЕНИЕ СДЕЛОК КАК ЕДИНЫЙ ЭЛЕМЕНТ СТАБИЛЬНОСТИ ГРАЖДАНСКОГО ОБОРОТА: НОВЕЛЛЫ ЗАКОНОДАТЕЛЬСТВА}

\section{Елена Витальевна Смиренская}

Санкт-Петербургский государственный университет, г. Санкт-Петербург, Российская Федерация

Введение: недвижимое имущество для всех участников гражданского оборота представляет собой основную, а для граждан иногда и единственную, материальную ценность, права на которую подлежат государственной регистрации. Вместе с тем одной государственной регистрации недостаточно для защиты прав и законных интересов собственников. Необходимы дополнительные гарантии. И такие гарантии может дать 
нотариальное удостоверение сделок с недвижимостью. Этот правовой механизм не является новым для нашего законодательства, но в силу отсутствия требований об обязательной нотариальной форме, к сожалению, почти не используется в гражданском обороте. В работе поставлена цель исследования взаимодействия двух правовых механизмов, направленных на стабильность гражданского оборота, на этапе реформирования гражданского законодательства. Методы: методологическую основу данного исследования составляет совокупность методов научного познания, среди которых основное место занимают сравнительноправовой метод и метод анализа. Результаты: в работе обоснована авторская позиция о необходимости установления норм об обязательном нотариальном удостоверении сделок с недвижимостью, которая опирается на последние изменения в законодательстве, а также научные и практические точки зрения. Выводы: в результате исследования выявлено прямое взаимодействие и взаимодополняемость между нотариальным удостоверением сделок и государственной регистрацией прав на недвижимое имущество как единый элемент стабильности и правомерности гражданского оборота. Установлено, что в своем единстве эти правовые механизмы позволяют защитить права и законные интересы собственника наилучшим образом, в том числе практически исключить дальнейшее оспаривание зарегистрированных прав.

Ключевые слова: права на недвижимое имущество, государственная регистрация недвижимости, нотариальное удостоверение сделок, сделки с недвижимостью, обязательная форма, порядок регистрации, Единая информационная система нотариата.

Цитирование. Смиренская Е. В. Институт государственной регистрации недвижимости и нотариальное удостоверение сделок как единый элемент стабильности гражданского оборота: новеллы законодательства // Legal Concept = Правовая парадигма. - 2019. - T. 18, № 1. - C. 30-39. - DOI: https://doi.org/ 10.15688/lc.jvolsu.2019.1.4

\section{Введение}

Система государственной регистрации прав на недвижимое имущество и сделок с ним существует в нашей стране уже 20 лет. Значение этой системы нельзя недооценивать. Однако последние несколько лет подряд все гражданское законодательство находится в активной стадии реформирования, которое не могло не затронуть правового регулирования гражданского оборота объектов недвижимости.

С принятием и вступлением в силу 31 января 1998 г. Закона о государственной регистрации прав недвижимого имущества и сделок с ним в нашем законодательстве связана отмена обязательной нотариальной формы для многих сделок. При этом следует признать, что государственная регистрация, как многие считали, должна была стать альтернативой нотариальному удостоверению. Однако практика показала, что институт государственной регистрации прав не может обеспечить полную защиту прав и законных интересов собственников, и в связи с этим постепенно стал возвращаться институт нотариального удостоверения сделок с недвижимостью.

Участие нотариусов создает дополнительные существенные правовые гарантии в сфере защиты прав и законных интересов участников рынка недвижимости. «Законность сделки можно обеспечить, только определив действительные намерения сторон и проверив, соответствуют ли эти намерения избранному ими виду сделки. А это можно установить только в беседе со сторонами сделки, по результатам которой нотариус, выявив интересы и действительные намерения сторон, предлагает тот или иной вид сделки, а также разъясняет им ее существо (гражданину, не имеющему специальных правовых познаний, невозможно, трудно определить, какую законную форму в конкретной ситуации следует применить)» [7].

В результате заключения сделки без участия нотариуса собственник может лишиться своего имущества помимо своей воли, договор от имени собственника может быть подписан не уполномоченным на то лицом, недобросовестный продавец может неоднократно распорядиться своей недвижимостью до регистрации первого договора об ее отчуждении. Помимо этого возможны и другие противоправные или недобросовестные с точки зрения гражданского права действия участников гражданского оборота.

При этом остается вопрос: как же соотносятся эти два правовых механизма - государственная регистрация прав на недвижимость и нотариальное удостоверение сделок с недвижимостью - между собой? 


\section{Особенности \\ государственной регистрации прав \\ на недвижимое имущество \\ и нотариального удостоверения сделок \\ с недвижимостью}

В соответствии с п. 1 ст. 8.1 ГК РФ [5] «в случаях, предусмотренных законом, права, закрепляющие принадлежность объекта гражданских прав определенному лицу, ограничения таких прав и обременения имущества (права на имущество) подлежат государственной регистрации» на основе принципов проверки законности оснований регистрации, публичности и достоверности государственного реестра. Права на имущество, подлежащие государственной регистрации, возникают, изменяются и прекращаются с момента внесения соответствующей записи в государственный реестр, если иное не установлено законом (п. 2 ст. 8.1 ГК РФ).

В соответствии с п. 3 ст. 8.1 ГК РФ [5] «в случаях, предусмотренных законом или соглашением сторон, сделка, влекущая возникновение, изменение или прекращение прав на имущество, которые подлежат государственной регистрации, должна быть нотариально удостоверена». В этом случае запись в государственный реестр может быть внесена по заявлению любой стороны сделки, в том числе через нотариуса.

Если право на имущество возникает, изменяется или прекращается на основании нотариально удостоверенной сделки, уполномоченный в соответствии с законом орган вправе (но не обязан) проверять законность соответствующей сделки. Лицо, указанное в государственном реестре в качестве правообладателя, признается таковым, пока в установленном законом порядке в реестр не внесена запись об ином. При возникновении спора в отношении зарегистрированного права лицо, которое знало или должно было знать о недостоверности данных государственного реестра, не вправе ссылаться на соответствующие данные.

При этом следует отметить, что Концепция развития гражданского законодательства очень жестко подвергла критике существовавшую до недавнего времени так называемую двойную регистрацию, когда не- обходимо было регистрировать и право, и сделку, лежащую в ее основании, одновременно. «Государственная регистрация сделок по сути дублировала регистрацию перехода прав, а экспертиза сделок, проводимая регистратором, осуществлялась формально, по документам» [4].

В связи с этим были внесены изменения в Гражданский кодекс РФ и другие нормативно-правовые акты, и количество сделок, подлежащих государственной регистрации, значительно сократилось.

В соответствии с новой редакцией ст. 131 ГК РФ именно право собственности и другие вещные права на недвижимые вещи, ограничения этих прав, их возникновение, переход и прекращение подлежат государственной регистрации в едином государственном реестре. В случаях, предусмотренных законом, наряду с государственной регистрацией могут осуществляться еще и специальная регистрация или учет отдельных видов недвижимого имущества.

Что же касается государственной регистрации сделок, то в соответствии со ст. 164 ГК РФ законодатель сохранил за собой право устанавливать такую возможность. При этом в ГК РФ нет никаких понятий, условий, оснований, когда сделка может требовать такой регистрации, а главное - зачем, то есть осталось неясным, для каких целей законодатель все-таки оставил институт государственной регистрации сделок и к чему относить государственную регистрацию: к условиям действительности сделки или только к моменту возникновения правовых последствий, как указано в ст. 164 ГК РФ.

На наш взгляд, формой сделки государственная регистрация точно не является, поскольку в соответствии со ст. 158 ГК РФ сделки совершаются устно или в письменной форме (простой или нотариальной). А вот согласно п. 3 ст. 1 Закона о государственной регистрации недвижимости [13] «государственная регистрация прав на недвижимое имущество это юридический акт признания и подтверждения возникновения, изменения, перехода, прекращения права определенного лица на недвижимое имущество или ограничения такого права и обременения недвижимого имущества». Государственная регистрация является един- 
ственным доказательством существования зарегистрированного права (п. 5 ст. 1 Закона о государственной регистрации недвижимости). И все. Это главное и единственное предназначение института государственной регистрации - быть единственным доказательством.

И вот здесь мы сразу видим принципиальное различие между государственной регистрацией и нотариальным удостоверением сделок. Нотариальное удостоверение - это форма сделки, условие ее действительности. И в законодательстве такое значение нотариального удостоверения для стабильности гражданского оборота отражено в последних изменениях.

Понятие нотариального удостоверения сделок содержится в ст. 163 ГК РФ в новой редакции: «Нотариальное удостоверение сделки означает проверку законности сделки, в том числе наличия у каждой из сторон права на ее совершение, и осуществляется нотариусом или должностным лицом, имеющим право совершать такое нотариальное действие, в порядке, установленном законом о нотариате и нотариальной деятельности». Следует согласиться с мнением, что «никакое иное должностное лицо не сможет заменить нотариуса в части проверки соответствия закону субъективной стороны сделок» [3].

Обязательное нотариальное удостоверение сделок устанавливается нормами закона, и таких случаев немало, например договор ренты и пожизненного содержания с иждивением. При этом для подавляющего большинства сделок с недвижимостью Гражданский кодекс РФ обязательного нотариального удостоверения не требует. Так, в соответствии со ст. 550 ГК РФ договор продажи недвижимости заключается в письменной форме путем составления одного документа, подписанного сторонами. Вместе с тем в соответствии с п. 2 ч. 2 ст. 163 ГК РФ нотариальное удостоверение сделок обязательно и в случаях, предусмотренных соглашением сторон, даже если по закону для сделок данного вида нотариальная форма не требуется.

Необходимо отметить, что, несмотря на однозначное отнесение законом нотариального удостоверения к виду письменной формы сделки [1], сам порядок нотариального удостоверения направлен на выполнение не толь- ко этого условия действительности. Главное, что нотариусы проверяют все условия действительности сделки: дееспособность участников, соответствие воли волеизъявлению и, конечно же, соответствие содержания сделки закону. Это подтверждается и Основами законодательства РФ о нотариате [9]. Так, ст. 54 устанавливает, что нотариус обязан «разъяснить сторонам смысл и значение представленного ими проекта сделки и проверить, соответствует ли его содержание действительным намерениям сторон и не противоречит ли требованиям закона».

Кроме того, в соответствии со ст. 55 Основ при удостоверении сделок, направленных на отчуждение или залог имущества, права на которое подлежат государственной регистрации (ст. 8.1 ГК РФ), нотариус проверяет принадлежность данного имущества лицу, его отчуждающему или закладывающему, за исключением случаев, если в соответствии со сделкой на момент ее совершения данное имущество еще не принадлежит этому лицу, а также отсутствие ограничений прав, обременений имущества или иных обстоятельств, препятствующих совершению этих договоров.

В связи с вышесказанным с 1 января 2015 г. сроки государственной регистрации были существенно сокращены [14]. Теперь государственная регистрация прав осуществляется в «три рабочих дня с даты приема или поступления в орган регистрации прав заявления на осуществление государственной регистрации прав и прилагаемых к нему документов на основании нотариально удостоверенной сделки, свидетельства о праве на наследство, свидетельства о праве собственности на долю в общем имуществе супругов, а в случае поступления таких заявления и документов в электронной форме - в течение одного рабочего дня, следующего за днем поступления соответствующих документов» (п. 9 ст. 16 Закона о регистрации недвижимости) [13]. «Регистрация прав на недвижимость осуществляется теперь по принципу системы одного окна» [8].

Следует отметить, что основания для отказа в государственной регистрации и в совершении нотариального действия также значительно отличаются. Так, первые носят исключительно формальный характер (ст. 27 За- 
кона о регистрации недвижимости), тогда как ст. 48 Основ законодательства РФ о нотариате [9] предусматривает не только формальные основания для отказа в совершении нотариального действия, но и если: совершение такого действия противоречит закону; с просьбой о совершении нотариального действия обратился недееспособный гражданин либо представитель, не имеющий необходимых полномочий; сделка, совершаемая от имени юридического лица, противоречит целям, указанным в его уставе или положении; сделка не соответствует требованиям закона; и др.

Значимым, на наш взгляд, является и то, что в соответствии с п. 3 ст. 66 Закона о регистрации недвижимости «орган регистрации прав не несет ответственность за убытки, причиненные в результате государственной регистрации прав на основании признанных судом недействительными свидетельства о праве на наследство, свидетельства о праве собственности на долю в общем имуществе супругов либо на основании нотариально удостоверенной сделки, которая признана судом недействительной или в отношении которой судом применены последствия недействительности ничтожной сделки». Поскольку вся ответственность возлагается на самого нотариуса, и гарантии этой ответственности, в том числе в виде обязательного страхования ответственности при осуществлении профессиональной деятельности, коллективного страхования, личного имущества нотариуса и компенсационного фонда Федеральной нотариальной палаты, установлены Основами законодательства о нотариате.

Еще одно очень существенное изменение в законодательстве связано с возможностью оспаривать, в том числе зарегистрированные права, и доказывать несоответствие записей ЕГРП. В п. 5 ст. 61 ГПК РФ закреплено, что обстоятельства, подтвержденные нотариусом при совершении нотариального действия, не требуют доказывания, если подлинность нотариально оформленного документа не опровергнута в порядке, установленном ст. 186 ГПК РФ, или не установлено существенное нарушение порядка совершения нотариального действия. Это означает, что при возникновении спора о зарегистрированных правах по нотариально удостоверенной сдел- ке действия органов регистрации однозначно будут считаться законными и действительными. Нотариальное удостоверение сделки, в свою очередь, также означает законность всех положений сделки, ясность всех положений договора для обеих сторон, наличие дополнительных доказательственных возможностей в суде. «Это означает, что оспорить нотариально удостоверенную сделку с недвижимостью теперь гораздо сложнее» [8]. Можно сказать, что в случае нотариального удостоверения сделки практически исключаются случаи признания заключаемых сделок недействительными по основаниям, связанным с пороком воли сторон сделки (в частности, совершение сделки гражданином, признанным недееспособным; гражданином, дееспособность которого ограничена; совершение сделки под влиянием обмана, насилия, угрозы, злонамеренного соглашения представителя одной стороны с другой стороной и др.).

\section{Нужна ли обязательная нотариальная форма сделок с недвижимостью?}

Ответ на этот вопрос для кого-то может показаться очень простым. Однако прежде, чем на него ответить, необходимо разобраться в том, что же изменится, если законодатель вернется к обязательной нотариальной форме отдельных видов сделок.

На сегодняшний день в России сформировался развитый рынок недвижимости. Темпы строительства жилья постоянно растут и уже превысили показатели конца советского периода. В связи с этим доля сделок с участием граждан (физических лиц) среди всех сделок с недвижимостью является весьма значительной. Следует признать, что граждане в своем большинстве не обладают глубокими юридическими знаниями, вследствие чего у них могут возникать разные трудности при заключении сделок; высока вероятность того, что они могут стать жертвами мошенников. При этом защитить интересы участников рынка зачастую бывает просто некому.

К сожалению, государственные регистраторы Федеральной службы регистрации, кадастра и картографии не осуществляют комплексного правового сопровождения сделки. Они лишь проверяют соответствие представ- 
ленных документов требованиям закона для государственной регистрации перехода или возникновения какого-либо права на недвижимое имущество. Адвокаты и юрисконсульты защищают интересы только одной стороны (их клиента), поэтому не являются беспристрастными по отношению к другой стороне сделки. В отличие от названных лиц нотариус представляет собой защитника интересов всех участников гражданского оборота.

Следует отметить, что до 31 января 1998 г. все сделки с имуществом подлежали нотариальному удостоверению. Однако позднее государство разрешило заключать договоры купли-продажи недвижимости в простой письменной форме. По мнению многих авторов, возможность заключать договоры в простой письменной форме способствовала росту криминала, а также распространению мошенничества на рынке недвижимости $[2 ; 10 ; 12]$. В этой связи сотрудники правоохранительных органов не раз заявляли о необходимости вернуть обязательное удостоверение сделок с недвижимостью [6]. Вернуться к этой практике предлагалось в 2012 2013 гг., когда принимался крупный пакет поправок к ГК РФ. Однако данное предложение вызвало масштабную критику юридического сообщества, и данная норма была исключена из пакета.

До сих пор требования о совершении всех сделок с недвижимостью исключительно в нотариальной форме в Гражданском кодексе РФ отсутствуют. Однако на сегодняшний день, если рассмотреть отдельные нормы не только других нормативно-правовых актов гражданского законодательства, но и других отраслей права, можно встретить другую практику и достаточно много сделок, в которых предметом является недвижимое имущество или доля в таком имуществе, и которые требуют нотариального удостоверения по действующему законодательству. Например, соглашение о разделе совместно нажитого имущества (п. 2 ст. 38 СК РФ), брачный договор (п. 2 ст. 41 СК РФ), сделки по отчуждению или договоры ипотеки долей в праве общей собственности на недвижимое имущество, в том числе при отчуждении или ипотеке всеми участниками долевой собственности своих долей по одной сделке (п. 1 ст. 42 Закона о государственной регистрации недвижимости), сделки, связанные с распоряжением недвижимым имуществом на условиях опеки, а также сделки по отчуждению недвижимого имущества, принадлежащего несовершеннолетнему гражданину или гражданину, признанному ограниченно дееспособным (п. 2 ст. 54 Закона о государственной регистрации недвижимости), и многие другие [8]. Следовательно, подчеркивая важность нотариального удостоверения, акцентировав внимание на осуществлении нотариусом проверки законности совершения сделки, в том числе на наличие у каждой из сторон права на ее совершение, ст. 163 ГК РФ не зря специально была дополнена п. 3, в котором установлено, что несоблюдение обязательной нотариальной формы сделки влечет ее ничтожность, а значит никаких правовых последствий, кроме последствий недействительности, без нотариального удостоверения не возникнет.

На этом основании совершенно не случайно при постепенном усилении роли и значения нотариата в хозяйственной деятельности было решено ввести в нескольких регионах страны пилотный проект - обязательную нотариальную форму договора отчуждения недвижимости (Санкт-Петербург, Хакасия, Адыгея, Астраханская, Вологодская, Курганская, Ленинградская, Свердловская, Челябинская, Ярославская и Новосибирская области, Краснодарский и Красноярский края). В других областях, к примеру в Нижегородской, при совершении сделки с объектом недвижимости сохранили свободу усмотрения - представить документы в простой письменной форме в Росреестр или удостоверить сделку у нотариуса. И это только первый шаг на пути повсеместного внедрения обязательной нотариально удостоверяемой формы сделок с недвижимостью.

Кроме того, с 1 февраля 2019 г. в соответствии со ст. 55 Основ законодательства РФ о нотариате после удостоверения договора, на основании которого возникает право на недвижимое имущество (долю в праве собственности на недвижимое имущество), подлежащее государственной регистрации, нотариус обязан незамедлительно, но не позднее окончания рабочего дня или в сроки, установленные сторонами в договоре, представить в элект- 
ронной форме заявление о государственной регистрации прав и прилагаемые к нему документы в орган регистрации прав, если стороны сделки не возражают против подачи такого заявления нотариусом. Таким образом, можно вообще не обращаться в Росреестр или в МФЦ для подачи и получения документов о праве собственности. Это можно сделать через нотариуса или его работника в рамках одного нотариального действия по удостоверению сделки.

Критики введения обязательной нотариальной формы для разных видов договора с недвижимостью обосновывают свою позицию различными доводами, однако при ближайшем рассмотрении все они легко опровергаются [12]. Например, они говорят, что нотариус не сможет защитить граждан от мошенников. Он не проверяет подлинность документов, а также не сможет предсказать появление третьих лиц, которые в будущем способны оспорить сделку. Вместе с тем повторимся, что в соответствии со ст. 163 ГК РФ нотариальное удостоверение сделки означает проверку законности сделки, в том числе наличия у каждой из сторон права на ее совершение. Что касается появления третьих лиц, то от данного обстоятельства не спасет ни государственная регистрация, ни, тем более, простая письменная форма.

Еще один аргумент связан с организацией нотариальной деятельности, а именно: сделки с недвижимостью регистрируются очень часто, из-за введения обязательного формы в конторах возникнут большие очереди, также гражданам придется тратить деньги на оплату услуг нотариуса [2]. На наш взгляд, данные доводы вообще абсурдны, поскольку количество нотариусов и нотариальных контор (около восьми тысяч по России) достаточно для того, чтобы не создавать очереди, а оплата нотариального тарифа императивно регулируется налоговым законодательством, а не рынком и договоренностями с риелторами, где стоимость юридических услуг непредсказуема и значительно превышает стоимость услуг нотариуса.

К определенно положительным моментам введения обязательной нотариальной формы для сделок с недвижимостью следует отнести:

- во-первых, участие в сделке независимой и незаинтересованной стороны, которая обязана разъяснить участникам ее смысл, значение и правовые последствия;

- во-вторых, нотариальное удостоверение сделки является надежным способом ее защиты. Причем это не формальная подстраховка, а реальный способ оградить себя от «несчастного случая». Нотариус устанавливает личность сторон, проверяет принадлежность передаваемой недвижимости, отсутствие запрещений на ее передачу. «Нотариальное удостоверение - это пожизненная правовая и финансовая гарантия прав собственника» [2];

- в-третьих, удостоверяя сделку, нотариус гарантирует ее законность, ответственность нотариуса застрахована, а трехуровневая система страхования позволяет возместить весь причиненный ущерб (вред, убытки) в результате действий нотариуса;

- в-четвертых, нотариус сам (по поручению сторон, но без их участия) подает и получает документы с целью государственной регистрации прав;

- в-пятых, обязательное нотариальное удостоверение сделок с недвижимостью однозначно уменьшит загрузку на судебную систему, так как сделки, удостоверенные нотариусом, намного реже оспариваются в судах $[2 ; 8 ; 12]$, и с этим трудно не согласиться.

Конечно, с некоторыми из аргументов можно спорить, поскольку, если участники имущественного оборота пожелают получить консультационную помощь от нотариуса и обеспечить себя дополнительными гарантиями, они вправе предусмотреть для своей сделки нотариальную форму (п. 2 ст. 163 ГК РФ), но ведь и при государственной регистрации сделок преследуются цели, аналогичные нотариальному удостоверению сделок.

Вместе с тем не стоит забывать о том, что главная задача системы государственной регистрации - обеспечивать ведение единого государственного реестра всех прав на объекты недвижимости, что имеет огромное значение для имущественного оборота и получения [11]. Данная деятельность является необходимой, но именно нотариусы, на наш взгляд, способны помочь органам государственной регистрации обеспечить достоверность и законность сведений в ЕГРП. 
Попытки ввести обязательную нотариальную форму для сделок с недвижимостью не прекращаются. Ежегодно появляются законопроекты, которые обосновывают такую необходимость. При этом в одном из отзывов Правительства России на очередной законопроект указывалось, что данные изменения ведут «К возникновению дополнительных издержек для оборота недвижимости». В частности, Правительство России придерживается мнения, что «обязательное нотариальное удостоверение сделок с недвижимостью ухудшит материальное положение малоимущих и социально не защищенных групп населения» [10]. С такой позицией трудно согласиться.

Нотариальное удостоверение сделки уберегает участников гражданского оборота от непредвиденных негативных последствий ее заключения, которые могут быть гораздо более значительными в материальном плане по сравнению со стоимостью нотариальных услуг. Помимо этого для ряда категорий лиц налоговым законодательством предусмотрены льготы по уплате нотариального тарифа, что минимизирует затраты на нотариальное удостоверение сделок.

Более того, уже существуют договоры, подлежащие обязательному нотариальному удостоверению. В самом Гражданском кодексе РФ (п. 3 и п. 5 ст. 8.1) «заложена основа для возвращения в российский оборот нотариальной формы сделки с недвижимостью» [4]. Тем самым следует признать необходимым в российском гражданском обороте прецедент обязательного нотариального удостоверения сделок.

\section{Выводы}

Институт государственной регистрации недвижимости и институт нотариального удостоверения сделок имеют разные функции и механизмы защиты прав и законных интересов правообладателей. Эти правовые механизмы нельзя противопоставлять друг другу. Перед ними стоит единая цель - стабильность гражданского оборота.

Государственная регистрация не может заменить нотариальное удостоверение, равно как и нотариальное удостоверение сделок не направлено на замену государственной регистрации. Наоборот. Нотариальное удостоверение сделок может помочь институту государственной регистрации прав в достижении поставленных перед органами государственной регистрации задач. Возвращение к обязательной нотариальной форме по всем сделкам с недвижимостью, или хотя бы тем, в которых участвуют граждане, позволит значительно сократить количество судебных споров и уголовных преступлений в сфере оборота недвижимого имущества.

Таким образом, мы видим, что и государственная регистрация, и нотариальное удостоверение сделок с недвижимостью являются сходными в некоторых моментах, но не стоит забывать об их особенностях. То есть упразднить государственную регистрацию и ввести обязательное нотариальное удостоверение сделок с недвижимостью является нелогичным, оставить все как есть - в условиях нарастающего товарооборота тоже является непродуманным шагом. Выходом из данной ситуации, на наш взгляд, является введение обязательной нотариальной формы сделок с недвижимостью при сохранении их государственной регистрации, документы на которую в обязательном порядке будет предоставлять нотариус и они не будут нуждаться в дополнительной проверке. В такой ситуации и гражданам будут предоставлены дополнительные гарантии, и государство сможет контролировать ситуацию в данной отрасли.

В деятельности нотариуса содержится значительная правозащитная составляющая. Многие принципы нотариальной защиты прав и законных интересов граждан совпадают с принципами судебной защиты, среди них, в частности, беспристрастность, независимость, справедливость. Недаром нотариальную деятельность именуют «бесспорным судопроизводством».

Расширение масштабов применения института нотариального удостоверения сделок одновременно с институтом государственной регистрации недвижимости будет иметь исключительно положительные последствия как непосредственно для самих участников гражданского оборота, так и для укрепления уровня правопорядка в целом. 


\section{СПИСОК ЛИТЕРАТУРЫ}

1. Абрамова, Е. Н. К вопросу о понятии формы сделки / Е. Н. Абрамова // Нотариус. - 2015. № 6. - С. 3-7.

2. Аристархов, В. Нотариальное удостоверение сделок с недвижимостью: за и против / В. Аристархов // Новости и аналитика рынка недвижимости. -2014 . - № 9 .

3. Арчугова, Е. А. Нотариальное удостоверение сделок / Е. А. Арчугова, Н. Ю. Рассказова, М. 3. Шварц ; отв. ред. Н. Ю. Рассказова. - М. : ФРПК, 2012. - 66 с. - (Серия «Библиотека "Нотариального вестника"»).

4. Бевзенко, Р. С. Принципиальные положения статьи 8.1 Гражданского кодекса РФ о государственной регистрации прав на имущество / Р. С. Бевзенко // Закон. - 2015. - № 4. - С. 29-38.

5. Гражданский кодекс Российской Федерации (часть первая) с последними изменениями, внесенными Федеральным законом от 29.07.2017 № 217-Ф3, вступившими в силу с 01.01.2019 (ред. 96). - Электрон. текстовые дан. - Режим доступа: http://logos-pravo.ru/grazhdanskiy-kodeks-gk-rfchast-1. - Загл. с экрана.

6. Егорова, М. Е. Совершенствование законодательства о нотариате: обзор последних изменений и дополнений / М. Е. Егорова // Нотариус. - 2015. № 4. - С. 9-12.

7. Жукова, Ю. Участие нотариусов создает правовые гарантии для участников рынка недвижимости : [интервью Президента Нотариальной палаты Самарской области Г.Ю. Николаевой] / Ю. Жукова // Интернет-портал города Самары «SamRU», 05.02.2018. - Режим доступа: https:// www.samru.ru/society/gost/67407.html. - Загл. с экрана.

8. Иншакова, А. О. Влияние обязательной нотариальной формы сделок с недвижимостью на стабильность гражданского оборота / А. О. Иншакова, Ю. С. Чулова // Вестник Волгоградской академии МВД России. - 2016. - № 1 (36). - С. 43-47.

9. Основы законодательства Российской Федерации о нотариате от 11.02.1993 № 4462-І с последними изменениями, внесенными Федеральным законом от 27.12.2018 № 528-Ф3 (ред. 75). - Электрон. текстовые дан. - Режим доступа: http:// pravo.gov.ru/proxy/ips/. - Загл. с экрана.

10. Пашина, А. Р. Нотариальное удостоверение сделок: от традиции к современному пониманию / А. Р. Пашина // Нотариус. - 2014. - № 5. - С. 19-23.

11. Сазонова, М. И. Взаимодействие нотариата и регистрационных органов как дополнительная функция по защите прав граждан и юридических лиц в сфере недвижимости / М. И. Сазонова // Регистрация прав на недвижимость : сборник. - М. :
Российская правовая академия Министерства юстиции РФ. - 2012. - № 7.

12. Тымчук, Ю. А. Преимущества обязательной нотариальной формы удостоверения сделок с недвижимостью // Мы и право : научно-практический журнал. - 2015. - № 4 (29), декабрь. - С. 36-38.

13. Федеральный закон «О государственной регистрации недвижимости» от 13 июля 2015 года № 218-ФЗ (в ред. от 25.12.2018) // Собрание законодательства РФ. - 2015. - № 29. - Ст. 4344.

14. Чефранова, Е. А. Новеллы законодательства: вектор на расширение участия нотариуса в обороте недвижимости / Е. А. Чефранова // Нотариальный вестник. - 2015. - № 3. - С. 3-9.

\section{REFERENCES}

1. Abramova E.N. K voprosu o ponyatii formy sdelki [To the Issue of the Transaction Form Concept]. Notarius [The Notary], 2015, no. 6, pp. 3-7.

2. Aristarkhov V. Notarialnoe udostoverenie sdelok s nedvizhimostyu: za i protiv [Notarial Certification of Real Estate Transactions: Pros and Cons]. Novosti i analitika rynka nedvizhimosti [News and Analytics of the Real Estate Market], 2014, no. 9.

3. Archugova E.A., Rasskazova N.Yu., Shvarts M.Z. Notarialnoe udostoverenie sdelok [Notarial Certification of Transactions]. Moscow, FRPK Publ., 2012. 66 p.

4. Bevzenko R.S. Printsipialnye polozheniya statyi 8.1 Grazhdanskogo kodeksa RF o gosudarstvennoy registratsii prav na imushchestvo [Basic Provisions of Clause 8.1 of the Civil Code of the Russian Federation on the State Registration of the Real Estate Rights]. Zakon [Law], 2015, no. 4, pp. 29-38.

5. Grazhdanskiy kodeks Rossiyskoy Federatsii (chast pervaya) s poslednimi izmeneniyami, vnesennymi Federalnym zakonom ot 29.07.2017 № 217-FZ, vstupivshimi v silu s 01.01.2019 goda (red. 96) [The Civil Code of the Russian Federation (Part One) with the Amendments of the Federal Law of 29 July 2017 No. 217-FZ entered into force on 01 Jan. 2019 (ed. 96)]. URL: http://logos-pravo.ru/ grazhdanskiy-kodeks-gk-rf-chast-1.

6. Egorova M.E. Sovershenstvovanie zakonodatelstva o notariate: obzor poslednikh izmeneniy i dopolneniy [Improvement of the Notariate Legislation: Review of the Last Changes and Additions]. Notarius [The Notary], 2015, no. 4, pp. 9-12.

7. Zhukova Yu. Uchastie notariusov sozdaet pravovye garantii dlya uchastnikov rynka nedvizhimosti: intervyu Prezidenta Notarialnoy Palaty Samarskoy oblasti G.Yu. Nikolaevoy [Participation of Notaries Creates Legal Safeguards for Real Estate Market Participants: Interview of Samara Region 
Notarial Chamber President G.Yu. Nikolaeva]. Internetportal goroda Samary «SamRU» [Internet Portal of the City of Samara "SamRU"], 05.02.2018. URL: https:// www.samru.ru/society/gost/67407.html8 (accessed 5 February2018).

8. Inshakova A.O., Chulova Yu.S. Vliyanie obyazatelnoy notarialnoy formy sdelok $\mathrm{s}$ nedvizhimostyu na stabilnost grazhdanskogo oborota [Impact of Mandatory Notarial Form of Real Estate Transactions on the Stability of Civil Turnover]. Vestnik Volgogradskoy akademii MVD Rossii [Bulletin of the Volgograd Russian Interior Ministry Academy], 2016, no. 1 (36), pp. 43-47.

9. Osnovy zakonodatelstva Rossiyskoy Federatsii o notariate ot 11 fevralya 1993 goda № 4462-I s poslednimi izmeneniyami, vnesennymi Federalnym zakonom ot 27.12.2018 № 528-FZ (red. 75) [Principles of the Russian Federation Notariate Legislation dated 11 Feb. 1993 Amended by the Federal Law dated 27 Dec. 2018 No. 528-FZ (ed.75)]. URL: http://pravo.gov.ru/proxy/ips/.

10. Pashina A.R. Notarialnoe udostoverenie sdelok: ot traditsii k sovremennomu ponimaniyu [Notarial Certification of Transactions: from Tradition to Modern Understanding]. Notarius [The Notary], 2014, no. 5. pp. 19-23.

11. Sazonova M.I. Vzaimodeystvie notariata i registratsionnykh organov kak dopolnitelnaya funktsiya po zashchite prav grazhdan i yuridicheskikh lits $\mathrm{v}$ sfere nedvizhimosti [Interaction of the Notariate and Registration Bodies as an Additional Function on Protecting Rights of Citizens and Legal Entities in the Sphere of Real Estate]. Registratsiya prav na nedvizhimost: Sbornik [Registration of the Rights for the Real Estate: Collection]. Moscow, Rossiyskaya pravovaya akademiya Ministerstva yustitsii RF Publ., 2012, no. 7.

12. Tymchuk Yu.A. Preimushchestva obyazatelnoy notarialnoy formy udostovereniya sdelok $\mathrm{s}$ nedvizhimostyu [Advantages of the Mandatory Notarial Form of the Certification of Real Estate Transactions]. My i pravo: nauchno-prakticheskiy zhurnal [We and Law: Scientific and Practical Journal], 2015, no. 4(29), December, pp. 36-38.

13. Federalnyy zakon «O gosudarstvennoy registratsii nedvizhimosti» ot 13.07.2015 No. 218-FZ (v red. ot 25 dekabrya 2018) [The Federal Law “On the State Registration of Real Estate" dated 13 July 2015 No. 218-FZ (ed. of 25 Dec. 2018)]. Sobranie zakonodatelstva $R F$ [The Collection of the Legislation of the Russian Federation], 2015, no. 29, art. 4344.

14. Chefranova E.A. Novelly zakonodatelstva: vektor na rasshirenie uchastiya notariusa $\mathrm{v}$ oborote nedvizhimosti [Innovations of the Legislation: Vector on Expanding Participation of Notaries in the Real Estate Turnover]. Notarialnyy vestnik [the Notarial Bulletin], 2015, no. 3, pp. 3-9.

\section{Information about the Author}

Elena V. Smirenskaya, Candidate of Sciences (Jurisprudence), Associate Professor, Department of Notariate, Saint Petersburg State University, Law Department (Basic Department of Saint Petersburg State University), Universitetskaya Emb., 7/9, 199034 Saint Petersburg, Russian Federation, smirenskayaelena@gmail.com, e.smirenskaya@spbu.ru,https://orcid.org/0000-0002-8600-7422

\section{Информация об авторе}

Елена Витальевна Смиренская, кандидат юридических наук, доцент кафедры нотариата, Санкт-Петербургский государственный университет, юридический факультет (базовая кафедра СПбГУ), Университетская наб., 7/9, 199034 г. Санкт-Петербург, Российская Федерация, smirenskayaelena@gmail.com, e.smirenskaya@spbu.ru,https://orcid.org/0000-0002-8600-7422 